\title{
Associations between urinary heavy metal concentrations and blood pressure in residents of Asian countries
}

\author{
Yuki Mizuno ${ }^{1 *} \mathbb{D}$, Hana Shimizu-Furusawa², Shoko Konishi' , Tsukasa Inaoka ${ }^{3}$, Sk Akhtar Ahmad ${ }^{4}$, \\ Makiko Sekiyama ${ }^{5}$, Oekan S. Abdoellah ${ }^{6}$, Budhi Gunawan ${ }^{6}$, Rajendra Prasad Parajuli ${ }^{7}$, Yukio Ikemoto $^{8}$, \\ Tran Dinh Lam ${ }^{9}$, Chiho Watanabe ${ }^{10}$ and Masahiro Umezaki ${ }^{1}$
}

\begin{abstract}
Background: Previous studies have suggested that exposures to heavy metals (arsenic, cadmium, lead, and selenium) may be associated with differences in blood pressure. However, the findings of these studies have been inconsistent. This study was performed to examine the associations between urinary heavy metal concentrations and blood pressure among residents of four Asian countries (Bangladesh, Indonesia, Nepal, and Vietnam).

Methods: This cross-sectional study examined 1899 adults in four Asian countries. Urinary concentrations of heavy metals were measured by inductively coupled plasma mass spectrometry. A questionnaire survey was administered regarding individual characteristics. Anthropometric measurements (height and weight) were performed. Systolic and diastolic blood pressures were measured after a short rest. Multiple linear regression models were applied to investigate associations between urinary heavy metal concentrations and blood pressure after adjustments for age, sex, and body mass index.
\end{abstract}

Results: The geometric means of the urinary concentrations of arsenic, cadmium, lead, and selenium were 84.6, $0.885,2.09$, and $16.5 \mu \mathrm{g} / \mathrm{g}$ creatinine, respectively. The urinary arsenic concentrations were slightly higher than those typically reported in non-polluted populations, while urinary cadmium, lead, and selenium concentrations were equivalent or slightly lower. The urinary lead concentrations were positively associated with both systolic and diastolic blood pressure, but urinary selenium concentrations were negatively associated with them.

Conclusions: Variations in the urinary concentrations of lead and selenium were associated with blood pressure at low levels of exposure/intake.

Keywords: Arsenic, Cadmium, Lead, Selenium, Blood pressure

\section{Background}

Blood pressure is defined as the pressure of circulating blood within arteries. Excessive energy or salt intake, lack of physical activity, and presence of psychological stress

*Correspondence: mizuno@humeco.m.u-tokyo.ac.jp

1 Department of Human Ecology, Graduate School of Medicine, The University of Tokyo, 7-3-1 Hongo, Bunkyo-ku, Tokyo 113-0033, Japan

Full list of author information is available at the end of the article are major risk factors for developing high blood pressure [1-4]. Hypertension, the state in which blood pressure exceeds a certain threshold, is an important risk factor for various cardiovascular diseases. More than 1 billion people have been diagnosed with hypertension worldwide [5].

Exposure to toxic heavy metals, e.g., arsenic (As), cadmium $(\mathrm{Cd})$, and lead $(\mathrm{Pb})$, may be associated with individual variations in blood pressure $[6,7]$. The biological original author(s) and the source, provide a link to the Creative Commons licence, and indicate if changes were made. The images or other third party material in this article are included in the article's Creative Commons licence, unless indicated otherwise in a credit line to the material. If material is not included in the article's Creative Commons licence and your intended use is not permitted by statutory regulation or exceeds the permitted use, you will need to obtain permission directly from the copyright holder. To view a copy of this licence, visit http://creativecommons.org/licenses/by/4.0/. The Creative Commons Public Domain Dedication waiver (http://creativeco mmons.org/publicdomain/zero/1.0/) applies to the data made available in this article, unless otherwise stated in a credit line to the data. 
mechanisms that drive heavy metal-induced blood pressure changes include Cd-induced nephrotoxicity [8-10], as well as increased cardiac output and vasoconstriction triggered by exposure of the sympathetic nervous system to $\mathrm{Pb}$ [11]. Furthermore, $\mathrm{As}, \mathrm{Cd}$, and $\mathrm{Pb}$ can damage endothelial cells by promoting inflammation and/or oxidative stress [12].

Selenium (Se), an essential trace element, may also affect blood pressure [13]. In humans, Se is a cofactor of glutathione peroxidase, a selenoprotein that acts as an antioxidative enzyme [14, 15], which can mitigate the toxicity of heavy metals by its antioxidative effects [16]. Glutathione peroxidase activity reduces lipid peroxidation, atherosclerotic plaque formation, and platelet aggregation [17-19]. Therefore, Se intake can reduce the risk of high blood pressure.

The results of several epidemiological studies investigating the relationships between blood pressure and exposure to $\mathrm{As}, \mathrm{Cd}, \mathrm{Pb}$, and $\mathrm{Se}$ have demonstrated contradictory results. For example, several reports described positive associations between blood pressure and exposure to $\mathrm{Cd}$ or $\mathrm{Pb}$ even in regions with known sources of contamination [20-24]. However, other studies found no associations $[20,25]$ or negative associations $[23,26$, 27]. While a positive association between As exposure and blood pressure in As-contaminated regions has been established [28-30], it remains unclear whether this association exists in non-contaminated settings. Furthermore, studies examining associations between Se status and blood pressure have reported negative associations $[31,32]$, positive associations [33, 34], and no associations [35-37]. These inconsistencies have not yet been fully explained. However, variables that vary among study populations (e.g., nutritional status) might confound the associations of toxic heavy metal exposure and Se intake with blood pressure.

Despite an investigation of the association between heavy metal exposure and blood pressure, the studies in non-contaminated settings are still scarce. Studies are also lacking in rural areas in Asia, where people would be more vulnerable to the heavy metal exposure due to their relatively poor nutritional status. Therefore, the aim of this study was to examine the associations between urinary concentrations of heavy metals (As, $\mathrm{Cd}, \mathrm{Pb}$, and $\mathrm{Se}$ ) and blood pressure among residents of four Asian countries. Additionally, this study investigated differences in the associations among the four countries, which were thought to have different heavy metal exposure levels.

\section{Methods}

\section{Study population and sampling}

This cross-sectional study was conducted by examining 2241 adults in Bangladesh, Indonesia, Nepal, and
Vietnam. Several farming communities with varied characteristics (e.g., reliance on subsistence farming and reliance on large-scale cash cropping) were selected in each country, and all de facto residents of each community were invited to participate in the study (see Table 1 for the characteristics of the target communities). We recruited individuals aged 18 years or older and had neither a high fever nor diarrhea on the survey days. Among the 2241 participants, blood pressure was not measured in 310, such that the final sample size was 1931.

Using face-to-face questionnaire surveys, the participants were asked about individual characteristics (e.g., sex and age). Anthropometric measurements (height and weight) were also performed. Systolic blood pressure $(S B P)$ and diastolic blood pressure $(D B P)$ were measured by a digital sphygmomanometer or a mercury manometer after a short period of rest. Additionally, a spot urine sample was collected for each participant.

We asked the participants to collect their spot urine samples using a urine cup and dispensed the samples into screw-capped polypropylene tubes. The tubes were washed with $15 \%$ nitric acid and rinsed with ultrapure water prior to sampling. The collected urine samples were frozen with dry ice, then transported to Japan, and stored at $-80^{\circ} \mathrm{C}$ until analysis.

Written informed consent was obtained from each participant before the survey. Ethics approval was obtained from the Ethics Committee of the Graduate School of Medicine at the University of Tokyo (No. 1505-(1)).

\section{Measurement of urinary heavy metal concentrations}

Urinary concentrations of As (mass-to-charge ratio $(\mathrm{m} / \mathrm{z}$ ) $=75), \mathrm{Cd}(m / z=111), \mathrm{Pb}(m / z=208)$, and $\mathrm{Se}(m / z=$ 78 ) were measured by inductively coupled plasma mass spectrometry (Agilent 7500ce). In brief, each urine sample was diluted 20 -fold with $1 \%$ nitric acid (60\%; Wako, Osaka, Japan) and 2\% 1-butanol (99.5\%; Nacalai Tesque, Kyoto, Japan), then filtered through a $0.45-\mu \mathrm{m}$ pore membrane. Urinary creatinine concentrations were measured using a spectrophotometric method based on Jaffe's reaction. To adjust for the dilution effect, the urinary concentration of each metal was divided by the creatinine concentration.

Urinary $\mathrm{Cd}$ concentrations reflect long-term Cd exposure (i.e., more than 10 years) [38, 39], while urinary As concentrations reflect relatively recent exposure to As (i.e., within several days) [40]. Data collected from individuals who consume seafood should be interpreted with caution, because their urinary As concentrations may reflect the consumption of organic As compounds, which are less toxic than inorganic As; thus, the As toxicity may be overestimated in seafood consumers [40]. Whole blood or serum is commonly used to assess exposure to 
Table 1 Characteristics of the target communities in this study

\begin{tabular}{lllll}
\hline Country & Community & $\boldsymbol{n}$ (male, female) & Location & Main occupation \\
\hline Bangladesh $(n=549)$ & BV & $107(51,56)$ & Urban & Tertiary industry \\
& BJ & $71(39,32)$ & Peri-urban & Farming (rice, vegetables, beans, and jute) \\
& BZ & $60(30,30)$ & Peri-urban & Farming (rice, vegetables, and mango) \\
& BS & $95(42,53)$ & Rural & Farming (rice, vegetables, and jute) \\
BT & $107(57,50)$ & Rural & Farming (rice, vegetables, and jute) and migrant labor \\
Indonesia $(n=186)$ & BC & $109(42,67)$ & Rural & Wage labor \\
Nepal $(n=700)$ & $100(50,50)$ & Rural & Farming (rice) \\
& S & $86(46,40)$ & Urban & Various occupations \\
& NC & $169(65,104)$ & Rural & Farming (rice and vegetables) and commerce, wage \\
Vietnam $(n=496)$ & NP & $123(54,69)$ & Rural & labor, and migrant labor \\
& NW & $161(70,91)$ & Urban & Commerce and wage labor \\
& NI & $128(59,69)$ & Rural & Cash-crop farming (tea, cardamon, and broom grass) \\
& NK & $119(55,64)$ & Peri-urban & Migrant labor, business, and farming (rice and mustard) \\
& VP & $134(66,68)$ & Rural & Cash-crop farming (coffee) \\
VA & $136(53,83)$ & Rural & Farming (rice and corn) \\
VT & $114(58,56)$ & Urban & Retail business and recycling industry
\end{tabular}

$n$, number of participants

$\mathrm{Pb}$ and the nutritional status of Se, respectively. Urinary concentrations of $\mathrm{Pb}$ and Se are correlated with the corresponding serum/blood concentrations or intake [4145]; therefore, we treated urinary concentrations of $\mathrm{Pb}$ and Se as alternative exposure/intake biomarkers.

The detection limits of urinary metal concentrations $(\mu \mathrm{g} / \mathrm{L})$ were 0.09 for $\mathrm{As}, 0.08$ for $\mathrm{Cd}, 0.11$ for $\mathrm{Pb}$, and 0.44 for Se in this study, corresponding to three times the standard deviation of the blank measurements $(n=5)$. Urinary As and Se were detected in all samples, while the detection rates were $93 \%$ and $94 \%$ for $\mathrm{Cd}$ and $\mathrm{Pb}$, respectively. The $\mathrm{Cd}$ and $\mathrm{Pb}$ concentrations of the participants in whom these elements were not detected were set at half of the detection limit value.

\section{Statistical analysis}

Of the 1931 participants, we obtained urine samples, anthropometric and blood pressure measurements, and questionnaire data (including sex and age) from 1899 individuals. Their data were used for the statistical analyses $(n=1899)$. There were 541 from Bangladesh, 177 from Indonesia, 690 from Nepal, and 491 from Vietnam.

Creatinine-adjusted urinary concentrations of $\mathrm{As}, \mathrm{Cd}$, $\mathrm{Pb}$, and $\mathrm{Se}$ were log-transformed to achieve approximately normal distributions; the log-transformed values were used in subsequent analyses. Differences in creatinine-adjusted urinary heavy metal concentrations among the four countries were assessed by one-way analysis of variance, followed by Tukey's multiple comparison test. Correlations among urinary heavy metal concentrations and those between urinary heavy metal concentrations and blood pressure were investigated by Pearson's correlation analysis. Following these bivariate analyses, to examine associations between urinary heavy metal concentrations and blood pressure, multiple linear regression models were performed for all participants (covariates: country, age, sex, and body mass index $(B M I)$ ) and then for the participants in each country. To examine multicollinearity among elements via multiple linear regression analysis, variance inflation factor (VIF) values were calculated; sensitivity analyses were also performed by including interaction terms between correlated elements. Another sensitivity analysis was performed by using the urinary creatinine concentration (log-transformed) as a covariate instead of the creatinine-adjusted urinary heavy metal concentrations, based on a previous suggestion [46]. All analyses were performed using R software (version 4.0.2).

\section{Results}

Table 2 shows the general characteristics of the study participants. There were slightly more female participants (54\%) than male participants (46\%) in all countries. The medians (interquartile ranges) for age and $B M I$ were $37(29-45)$ years and $21(19-23) \mathrm{kg} / \mathrm{m}^{2}$, respectively, for all participants. With regard to blood pressure, overall 
Table 2 General characteristics of all study participants and by country

\begin{tabular}{|c|c|c|c|c|c|c|}
\hline Characteristics & & All countries $(n=1899)$ & Bangladesh $(n=541)$ & Indonesia $(n=177)$ & Nepal $(n=690)$ & Vietnam $(n=491)$ \\
\hline \multirow[t]{2}{*}{$\operatorname{Sex}^{\mathrm{a}}$} & Male & $874(46)$ & $258(48)$ & $90(51)$ & $300(43)$ & $386(48)$ \\
\hline & Female & $1025(54)$ & $283(52)$ & $87(49)$ & $390(57)$ & $414(52)$ \\
\hline Age $\left(\right.$ years) ${ }^{b}$ & & $37(29-45)$ & $35(27-45)$ & $41(35-46)$ & $35(26-45)$ & $39(33-46)$ \\
\hline$B M I\left(\mathrm{~kg} / \mathrm{m}^{2}\right)^{b}$ & & $21(19-23)$ & $20(18-22)$ & $22(20-24)$ & $22(19-24)$ & $20(18-22)$ \\
\hline Overweight ${ }^{\mathrm{a}, \mathrm{c}}$ & & $224(12)$ & $46(9)$ & $34(20)$ & $120(17)$ & $24(5)$ \\
\hline Obesity $^{\mathrm{a}, \mathrm{d}}$ & & $27(1)$ & $3(1)$ & $5(3)$ & $17(2)$ & $2(0)$ \\
\hline$S B P(m m H g)^{b}$ & & $119(109-131)$ & $119(109-130)$ & $122(113-136)$ & $118(108-131)$ & $119(110-131)$ \\
\hline$D B P(\mathrm{mmHg})^{b}$ & & $77(69-85)$ & $75(68-83)$ & $78(73-88)$ & $79(72-88)$ & $75(68-84)$ \\
\hline Hypertension ${ }^{a, e}$ & & $383(20)$ & $86(16)$ & $43(24)$ & $156(23)$ & $81(17)$ \\
\hline
\end{tabular}

Abbreviations: $B M I$, body mass index; $S B P$, systolic blood pressure; $D B P$, diastolic blood pressure

${ }^{a} n(\%),{ }^{b}$ median (internal quartile range: quartile 1-quartile 3), ${ }^{c}$ overweight: $25 \mathrm{~kg} / \mathrm{m}^{2} \leq B M I<30 \mathrm{~kg} / \mathrm{m}^{2}$, dobesity: $B M I \geq 30 \mathrm{~kg} / \mathrm{m}^{2},{ }^{\mathrm{e}} \mathrm{hypertension}$ : $S B P \geq 140 \mathrm{mmHg}$ and/or $D B P \geq 90 \mathrm{mmHg}$

medians (interquartile ranges) were 119 (109-131) and 77 (69-85) $\mathrm{mmHg}$ for $S B P$ and $D B P$, respectively. Overall, $13 \%$ of the participants were considered overweight $\left(25 \leq B M I<30 \mathrm{~kg} / \mathrm{m}^{2}\right)$ or obesity $\left(B M I \geq 30 \mathrm{~kg} / \mathrm{m}^{2}\right)$, while $20 \%$ of participants had hypertension $(S B P \geq 140$ $\mathrm{mmHg}$ and/or $D B P \geq 90 \mathrm{mmHg}$ ).

Table 3 shows the urinary concentrations of As, Cd, $\mathrm{Pb}$, and Se among the participants; creatinine-adjusted values are also shown. In all participants, the geometric means (GMs) (geometric standard deviations) of creatinine-adjusted urinary heavy metal concentrations were $84.6(2.52) \mu \mathrm{g} / \mathrm{g}$ creatinine for As, 0.885 (2.84) $\mu \mathrm{g} / \mathrm{g}$ creatinine for $\mathrm{Cd}, 2.09(3.63) \mu \mathrm{g} / \mathrm{g}$ creatinine for $\mathrm{Pb}$, and 16.5 (1.64) $\mu \mathrm{g} / \mathrm{g}$ creatinine for Se. Participants in Bangladesh had the highest creatinine-adjusted urinary concentrations of $\mathrm{As}, \mathrm{Cd}$, and $\mathrm{Pb}$, but had the lowest urinary Se concentrations. The participants in Vietnam had the highest urinary concentrations of Se.
Pearson's correlation coefficients between urinary metal concentrations are shown in Table 4. The strongest correlation was found between As and Se $(r=0.39)$, followed by As and $\mathrm{Cd}(r=0.34)$. Other correlations were weaker $(r=0.13-0.32)$, although the coefficients were statistically significant $(p<0.001)$.

The results of correlation analyses and scatter plots of urinary heavy metal concentrations and blood pressures are shown in Table 5 and Figure S1, respectively. SBP was positively correlated with urinary $\mathrm{Cd}$ concentration. $D B P$ was negatively correlated with urinary As and Se concentrations.

Table 6 presents the results of multiple linear regression analyses examining the associations between urinary heavy metal concentrations and blood pressure in all participants (covariates: country, age, sex, and $B M I$ ). Statistically significant associations were not found between urinary As concentrations and blood pressure. Urinary

Table 3 Urinary metal concentrations of all study participants and by country

\begin{tabular}{|c|c|c|c|c|c|}
\hline Metals & $\begin{array}{l}\text { All countries ( } n \\
=1899)\end{array}$ & Bangladesh $(n=541)$ & Indonesia $(n=177)$ & Nepal $(n=690)$ & Vietnam $(n=491)$ \\
\hline \multicolumn{6}{|c|}{ Unadjusted ( $\mu \mathrm{g} / \mathrm{L})$} \\
\hline Arsenic & $56.2(2.87)$ & $85.0(2.54)$ & $53.1(2.16)$ & $26.2(2.09)$ & $107(2.64)$ \\
\hline Cadmium & $0.612(3.02)$ & $0.786(2.78)$ & $0.507(2.56)$ & $0.387(2.66)$ & $0.942(3.19)$ \\
\hline Lead & $1.44(3.61)$ & $2.80(2.99)$ & $0.840(3.72)$ & $1.07(3.05)$ & $1.29(4.08)$ \\
\hline Selenium & $11.0(2.51)$ & $9.73(2.13)$ & $18.1(2.26)$ & $7.23(2.45)$ & $19.0(2.23)$ \\
\hline \multicolumn{6}{|c|}{$\begin{array}{l}\text { Creatinine-adjusted } \\
\text { ( } \mathrm{gg} / \mathrm{g} \text { creatinine) }\end{array}$} \\
\hline Arsenic $^{\mathrm{a}}$ & $84.6(2.52)$ & $134(2.35)^{a}$ & $47.7(1.85)^{\beta}$ & $49.5(2.01)^{\beta}$ & $133(2.33)^{a}$ \\
\hline Cadmium $^{a}$ & $0.885(2.84)$ & $1.22(2.73)^{a}$ & $0.436(2.04)^{r}$ & $0.684(2.75)^{\beta}$ & $1.15(2.75)^{a}$ \\
\hline Lead $^{\mathrm{a}}$ & $2.09(3.63)$ & $4.41(3.23)^{a}$ & $0.698(2.89)^{\delta}$ & $1.95(2.97)^{\beta}$ & $1.49(3.67)^{\gamma}$ \\
\hline Selenium ${ }^{\mathrm{a}}$ & $16.5(1.64)$ & $15.3(1.55)^{\beta}$ & $16.3(1.37)^{\beta}$ & $13.7(1.50)^{\gamma}$ & $23.7(1.71)^{a}$ \\
\hline
\end{tabular}

Geometric mean (geometric standard deviation)

${ }^{a}$ Results of Tukey's multiple comparison test. Different letters indicate significant differences for each metal between countries $(a>\beta>\gamma>\delta)$ 
Table 4 Pearson's correlation coefficients between the urinary metal concentrations ${ }^{\mathrm{a}}(n=1899)$

\begin{tabular}{lllll}
\hline & Arsenic & Cadmium & Lead & Selenium \\
\hline Arsenic & - & & & \\
Cadmium & 0.31 & - & & \\
Lead & 0.16 & 0.32 & - & \\
Selenium & 0.39 & 0.34 & 0.13 & - \\
\hline
\end{tabular}

${ }^{a}$ Correlation coefficient between log-transformed and creatinine-adjusted concentrations. All the coefficients were statistically significant $(p<0.001)$

concentration of $\mathrm{Pb}$ was positively associated with both $S B P$ and $D B P$, while urinary Se concentration of Se was negatively associated with them. All values of VIF were less than 1.3, so it was unlikely that there was multicollinearity in the multiple linear regression models. Additionally, we performed sensitivity analyses by using urinary creatinine concentration (log-transformed) as a covariate

Table 5 Correlations between urinary heavy metal concentrations and blood pressure in all participants $(n=1899)$

\begin{tabular}{llllll}
\hline & \multicolumn{2}{l}{$S B P(\mathbf{m m H g})$} & & \multicolumn{2}{l}{$D B P(\mathbf{m m H g})$} \\
\cline { 2 - 3 } \cline { 5 - 6 } & $r^{\mathbf{b}}$ & $(95 \% \mathrm{Cl})$ & & $r^{\mathbf{b}}$ & $(95 \% \mathrm{Cl})$ \\
\hline Arsenic $^{\mathrm{a}}$ & -0.04 & $(-0.08,0.01)$ & & -0.15 & $(-0.20,-0.11)^{* * *}$ \\
Cadmium $^{\mathrm{a}}$ & 0.05 & $(0.01,0.10)^{*}$ & & 0.00 & $(-0.04,0.05)$ \\
Lead $^{\mathrm{a}}$ & 0.04 & $(-0.01,0.08)$ & 0.03 & $(-0.01,0.08)$ \\
Selenium $^{\mathrm{a}}$ & -0.02 & $(-0.06,0.03)$ & -0.06 & $(-0.10,-0.01)^{* *}$ \\
\hline
\end{tabular}

Abbreviations: $S B P$, systolic blood pressure; $D B P$, diastolic blood pressure; $C l$, confidence interval

${ }^{a}$ Creatinine-adjusted concentration ( $\mu \mathrm{g} / \mathrm{g}$ creatinine) (log-transformed)

${ }^{b}$ Pearson's correlation coefficient

${ }^{*}<0.05,{ }^{* *}<0.01,{ }^{* * *}<0.001$

Table 6 Associations between urinary metal concentrations and blood pressure in all participants $(n=1899)$

\begin{tabular}{|c|c|c|c|c|}
\hline & \multicolumn{2}{|c|}{$S B P(\mathrm{mmHg})$} & \multicolumn{2}{|c|}{$D B P(\mathrm{mmHg})$} \\
\hline & Coef. & $(95 \% \mathrm{Cl})$ & Coef. & $(95 \% C l)$ \\
\hline Arsenic $^{a}$ & 0.35 & $(-0.68,1.38)$ & -0.27 & $(-0.96,0.42)$ \\
\hline Cadmium $^{a}$ & 0.14 & $(-0.73,1.02)$ & 0.35 & $(-0.23,0.94)$ \\
\hline Lead $^{a}$ & 0.75 & $(0.07,1.42)^{*}$ & 0.56 & $(0.11,1.01)^{*}$ \\
\hline Selenium ${ }^{a}$ & -2.50 & $(-4.40,-0.61)^{* *}$ & -1.60 & $(-2.88,-0.33)^{*}$ \\
\hline Age (years) & 0.46 & $(0.39,0.52)^{* * *}$ & 0.19 & $(0.15,0.23)^{* * *}$ \\
\hline Sex (ref. = female) & 4.64 & $(3.08,6.20)^{* * *}$ & 0.60 & $(-0.44,1.65)$ \\
\hline$B M I\left(\mathrm{~kg} / \mathrm{m}^{2}\right)$ & 1.36 & $(1.12,1.60)^{* * *}$ & 1.18 & $(1.02,1.34)^{* * *}$ \\
\hline
\end{tabular}

Abbreviations: $S B P$, systolic blood pressure; $D B P$, diastolic blood pressure; $C l$, confidence interval; $B M I$, body mass index

Multiple linear regression models were adjusted by country

${ }^{a}$ Creatinine-adjusted concentration ( $\mu \mathrm{g} / \mathrm{g}$ creatinine) (log-transformed)

${ }^{*}<0.05,{ }^{* *}<0.01,{ }^{* * *}<0.001$ instead of creatinine-adjusted urinary heavy metal concentrations and including interaction terms between either toxic heavy metals $(\mathrm{As}, \mathrm{Cd}$, and $\mathrm{Pb}$ ) or Se; none of the urinary creatinine concentration and the interaction terms was statistically significant, and overall associations between urinary heavy metals and blood pressure did not change (Tables S1 and S2).

Figure 1 shows the results of multiple linear regression analyses that evaluated the associations between urinary heavy metal concentrations and blood pressure in each country (see Table S3 for details). Associations between urinary $\mathrm{Cd}$ concentrations and blood pressure differed by country: urinary $C d$ concentrations were positively associated with $S B P$ and $D B P$ in Nepal, while urinary $\mathrm{Cd}$ concentrations were negatively associated with $S B P$ and $D B P$ in Bangladesh. Other country-specific associations included a negative association between urinary As concentrations and $D B P$ in Nepal, a positive association between urinary $\mathrm{Pb}$ concentrations and $S B P / D B P$ in Bangladesh, and a negative association between urinary Se concentrations and both $S B P / D B P$ in Vietnam.

\section{Discussion}

\section{Urinary heavy metal concentrations among the participants}

Urinary As concentrations observed in the present study ( $G M=84.6 \mu \mathrm{g} / \mathrm{g}$ creatinine) fell between those reported in As-polluted regions such as in Bangladesh ( $G M=$ $204 \mu \mathrm{g} / \mathrm{g}$ creatinine for men and $219 \mu \mathrm{g} / \mathrm{g}$ creatinine for women [47]) and China $(G M=288.4 \mu \mathrm{g} / \mathrm{g}$ creatinine [48]), and those reported in non-polluted regions such as in the USA ( $G M=16.9 \mu \mathrm{g} / \mathrm{g}$ creatinine [49]). The urinary $\mathrm{Cd}$ and $\mathrm{Pb}$ concentrations among participants (GMs for $\mathrm{Cd}$ and $\mathrm{Pb}=0.885$ and $2.09 \mu \mathrm{g} / \mathrm{g}$ creatinine, respectively) were comparable to or slightly lower than the values previously reported in non-polluted regions in the east and southeast Asia (GMs: Cd = $1.26 \mu \mathrm{g} / \mathrm{g}$ creatinine [50] and $\mathrm{Pb}=3.59 \mu \mathrm{g} / \mathrm{g}$ creatinine [51]). We targeted participants who had slightly higher urinary As concentrations and equal or slightly lower urinary $\mathrm{Cd} / \mathrm{Pb}$ concentrations, compared with those in non-polluted populations. The urinary Se concentrations $(G M=16.5 \mu \mathrm{g} / \mathrm{g}$ creatinine) were lower than those reported for regions in Japan (GM $=37.5 \mu \mathrm{g} / \mathrm{g}$ creatinine for men and 45.7 for women [52]) or in China $(G M=38.3 \mu \mathrm{g} / \mathrm{g}$ creatinine [53]), where Se deficiency is not recognized.

\section{Associations between urinary heavy metal concentrations and blood pressure}

In this study, we examined associations between urinary heavy metal concentrations and blood pressure among residents of four Asian countries. Urinary $\mathrm{Pb}$ concentrations were positively associated with both $S B P$ and $D B P$, 


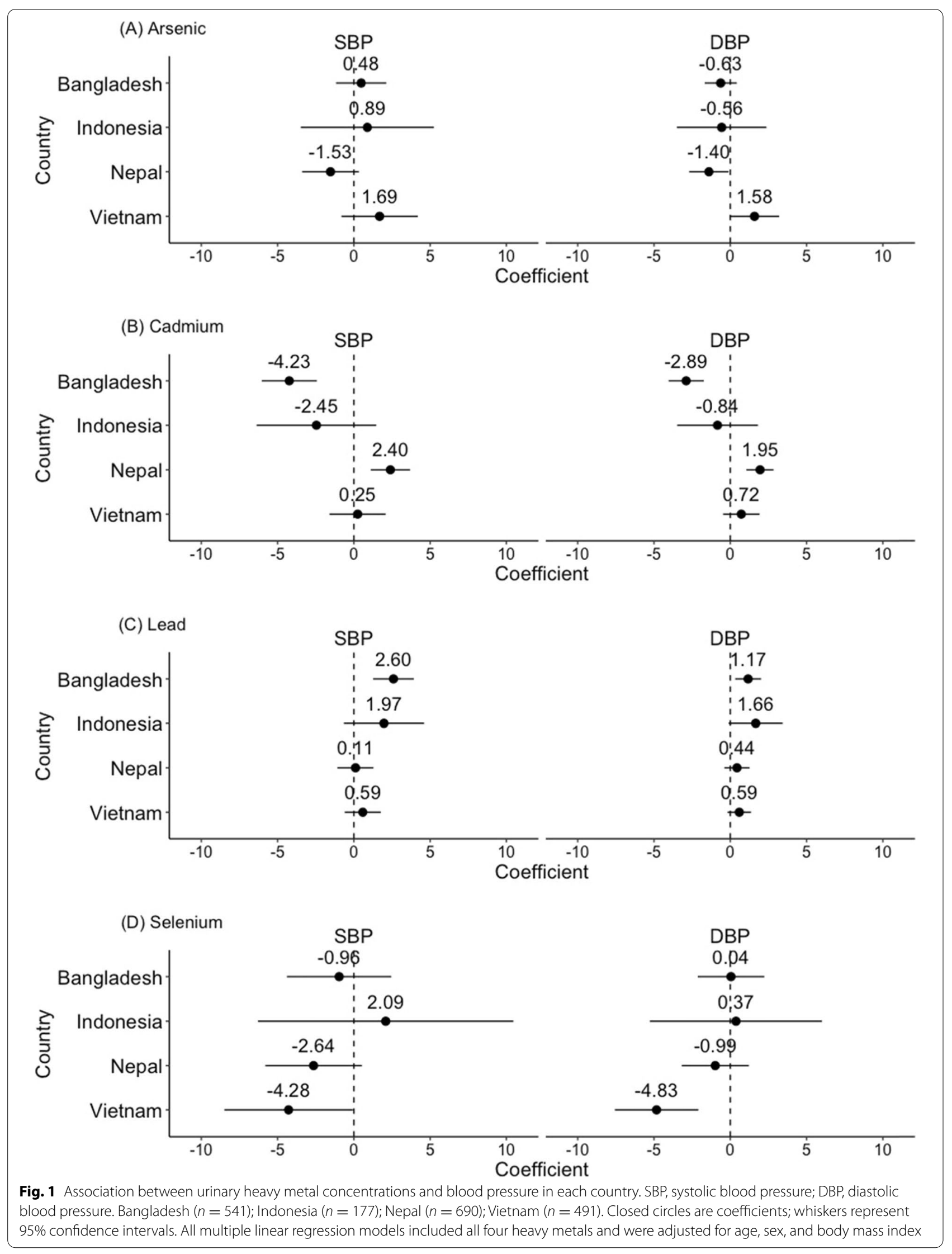


while urinary Se concentrations were negatively associated with them.

Our findings of the positive associations between urinary $\mathrm{Pb}$ concentrations and blood pressure agree with previous studies conducted in non-contaminated settings in the USA [54-56], Taiwan [7], and Sweden [22]. Kidney dysfunction due to $\mathrm{Pb}$ toxicity is presumably an important contributor to hypertension [10, 57-59]. Increased cardiac output and vasoconstriction are possible effects of $\mathrm{Pb}$ exposure [11]. Upon absorption into the human body, $\mathrm{Pb}$ can damage endothelial cells by promoting inflammation and/or oxidative stress $[11,12,60$, 61]. Lead can influence the activity of endothelial nitric oxide synthase in blood vessels, thereby suppressing vascular relaxation [11, 62]. Notably, some previous studies have reported no or negative associations between urine or blood $\mathrm{Pb}$ concentrations and blood pressure [20, 26]; these inconsistencies could not be explained by differences in the $\mathrm{Pb}$ exposure ranges $[7,22,54-56]$.

The present study revealed negative associations between urinary Se concentrations and blood pressure. According to a recent systematic review, harmful effects of Se on blood pressure were more likely to occur in populations with high Se intake, while protective effects were observed in Se-deficient populations [13]. Indeed, in a study that involved residents of an area with Se-rich soil and water, positive associations were found between blood pressure and the Se concentrations of serum, nails, and hair [34]. By contrast, in populations likely to include Se-deficient individuals, negative associations between Se intake and blood pressure were found [31, 32, 63]. These negative associations are likely related to the activation of the antioxidative enzyme GPx, for which Se is a cofactor $[14,15]$. Increased GPx activity reduces lipid peroxidation, atherosclerotic plaque formation, and platelet aggregation [17-19]. Because the participants in the present study exhibited relatively low urinary Se concentrations, we propose that individuals with higher Se nutritional status could have had increased GPx activity, which potentially contributed to their lower blood pressure.

Two previous studies reported positive associations between urinary As concentrations and blood pressure in As-polluted regions of Bangladesh and China [64, 65]. Other studies also reported positive correlations between urinary As concentrations and blood pressure, including in populations where urinary As concentrations fell within the non-contaminated range $[20,54,66]$. Only one study found a negative association between As concentrations and blood pressure in Argentina [28]. Furthermore, some studies found no association between As concentrations and blood pressure [25, 55], consistent with our results. Although previous studies found that high urinary As concentrations tended to be associated with blood pressure, the direction of the association remains unclear, especially in populations exposed to relatively low levels of As. Inorganic As metabolism varies between individuals because of genetic polymorphisms in the As ( +3 oxidation state) methyltransferase gene [67]. This suggests that susceptibility to As toxicity may vary among individuals, which could have led to the conflicting results in the literature.

Unexpectedly, no significant associations were found between urinary $\mathrm{Cd}$ concentrations and blood pressure in this study; similar results were reported in a contaminated setting in Bangladesh [25] and in a non-contaminated setting in the USA [54-56], while other studies conducted in non-contaminated settings reported positive $[20,21,23,24]$ and negative [26, 27] associations. The reasons for these inconsistencies among populations have not been clarified.

\section{Country-specific associations between urinary heavy metal concentrations and blood pressure}

A notable finding of this study was that the positive associations between urinary $\mathrm{Cd}$ concentrations and $S B P / D B P$ in Nepal and negative associations in Bangladesh; these differed from the overall trend found in our analyses of all countries. Positive associations between urinary $\mathrm{Cd}$ concentrations and blood pressure have frequently been reported in the previous studies $[20,21,23$, 24]; Cd-induced nephrotoxicity [8-10] and/or endothelial damage [12] were proposed as explanations. By contrast, the negative associations, as observed in Bangladesh, have also been found, but in far fewer studies [26, 27]. Although the biological mechanisms contributing to the negative association between urinary $\mathrm{Cd}$ concentrations and blood pressure are currently unclear, there are some possible explanations related to kidney function. Urinary $\mathrm{Cd}$ concentrations were positively associated with kidney function biomarkers (e.g., estimated glomerular filtration rate) under moderate $\mathrm{Cd}$ exposure levels among individuals experiencing high co-exposure to $\mathrm{Pb}$ [68]. This implies that urinary Cd excretion is affected by kidney dysfunction due to simultaneous exposure to $\mathrm{Pb}$ [69]. As discussed above, kidney dysfunction is a major factor in high blood pressure. Study participants in Bangladesh had higher urinary $\mathrm{Cd}$ and $\mathrm{Pb}$ concentrations, compared with participants in other countries, and therefore, the negative associations between urinary $\mathrm{Cd}$ concentrations and blood pressure could have been caused by confounding kidney dysfunction. Future studies should examine the association between $\mathrm{Cd}$ exposure and blood pressure with an additional assessment of kidney status. 
In this study, we found several other country-specific associations between urinary $\mathrm{As}, \mathrm{Pb}$, and Se concentrations and blood pressure. For example, urinary $\mathrm{Pb}$ concentrations were positively associated with $S B P$ and $D B P$ in Bangladesh, probably because of a higher level of $\mathrm{Pb}$ exposure (urinary $\mathrm{Pb}$ concentrations were highest in Bangladesh). A systematic review reported that a doseresponse relationship between $\mathrm{Pb}$ exposure and blood pressure has not been fully characterized [70]. It is possible that $\mathrm{Pb}$ affects blood pressure only when the exposure exceeds a certain threshold. The inconsistencies among countries were probably caused by country-specific differences in factors such as nutritional status/intake or physical activity; further investigations are needed to confirm this. In addition, the relatively small sample sizes after stratification by country may have increased the risks of type II errors in the statistical analysis.

\section{Strengths and limitations}

The main strength of this study was that the urine samples were collected in 17 communities with various characteristics across four Asian countries; this enabled an independent investigation of associations between urinary heavy metal concentrations and blood pressure at the local level. Study limitations included measuring the total As concentrations of the urine samples without speciation analysis to distinguish between exposure to toxic inorganic As and non-toxic organic As compounds. In addition, we assessed heavy metal exposure levels using single spot urine samples. To assess the systemic body burdens of $\mathrm{Pb}$ and $\mathrm{Se}$, it may have been beneficial to examine their concentrations in whole blood, erythrocytes, or serum/plasma samples [71, 72]. Furthermore, we failed to include some other potential confounders, such as nutrient intakes, smoking/drinking habits, socioeconomic status, and a kidney function marker. Finally, we did not collect information on chronic illnesses, medication, or hospital attendance. The use of anti-hypertensive medications was especially a crucial factor associated with blood pressure, although we speculate that few people used such medications in our study populations based on communications with the village leaders.

\section{Conclusions}

We found that urinary $\mathrm{Pb}$ concentration was positively associated with $S B P$ and $D B P$ in residents of four Asian countries. Notably, this association was present in the context of low urinary $\mathrm{Pb}$ concentrations, supporting the toxicity of $\mathrm{Pb}$ in terms of blood pressure among populations in non-contaminated areas. In contrast, urinary Se concentrations were negatively associated with $S B P$ and $D B P$, implying that Se is protective against increases in blood pressure.

\section{Supplementary Information}

The online version contains supplementary material available at https://doi. org/10.1186/s12199-021-01027-y.

Additional file 1: Figure S1. Scatterplot between urinary heavy metal concentrations and blood pressure $(n=1899)$.

Additional file 2: Table S1. Associations between urinary metal concentrations and blood pressure in all participants, with urinary creatinine concentration included as a covariate $(n=1899)$. Table S2. Associations between urinary heavy metal concentrations and blood pressure in all participants: interaction between toxic heavy metals and selenium ( $\mathrm{n}=$ 1899). Table S3. Country-specific associations between urinary heavy metal concentrations and blood pressure.

\section{Acknowledgements}

The authors thank all the participants and local staff members in this study for their cooperation.

\section{Authors' contributions}

YM, CW, and MU conceptualized this study. HSF, SK, TI, SAA, MS, OSA, BG, RPP, $\mathrm{YI}, \mathrm{TDL}, \mathrm{CW}$, and $\mathrm{MU}$ carried out the project and conducted the sampling. CW was the principal investigator of the project. HSF measured urinary heavy metal concentrations. YM and MU performed statistical analyses and wrote the first draft. YM, HSF, SK, SAA, OSA, RPP, CW, and MU edited the manuscript. All authors read and approved the final manuscript.

\section{Funding}

This study was supported by the Environment Research and Technology Development Fund; the Ministry of Environment, Japan (H-063); and JSPS KAKENHI Grant Numbers 21406021, 19H03315, 20K21443, and 21J12785.

\section{Availability of data and materials}

The datasets used and/or analyzed during the current study are available from the corresponding author on reasonable request.

\section{Declarations}

Ethics approval and consent to participate

The study has been approved by the Ethics Committee of the Graduate School of Medicine at the University of Tokyo (No. 1505-(1)). The informed consent to participate in the study was signed by all the participants prior to the survey.

\section{Consent for publication}

Not applicable.

\section{Competing interests}

The authors declare that they have no competing interests.

\section{Author details}

${ }^{1}$ Department of Human Ecology, Graduate School of Medicine, The University of Tokyo, 7-3-1 Hongo, Bunkyo-ku, Tokyo 113-0033, Japan. ${ }^{2}$ Department of Analytic Human Pathology, Nippon Medical School, 1-1-5, Sendagi, Bunkyo-ku, Tokyo 113-8602, Japan. ${ }^{3}$ Department of Human Ecology, Faculty of Agriculture, Saga University, 1 Honjo Machi, Saga 840-0052, Japan. ${ }^{4}$ Department of Occupational and Environmental Health, Bangladesh University of Health Sciences (BUHS), Darus Salam Mirpur-1, Dhaka 1216, Bangladesh. ${ }^{5}$ Health and Environmental Risk Division, National Institute for Environmental Studies, Onogawa 16-2, Tsukuba, Ibaraki 305-8506, Japan. ${ }^{6}$ Department of Anthropology, Faculty of Social and Political Science, Universitas Padjadjaran, Jl. Raya Bandung-Sumedang Km. 21 Jatinangor, Sumedang, West Java Province 45363, Indonesia. ${ }^{7}$ Central Department of Zoology, Central Campus, Institute of Science \& Technology (IOST), Tribhuvan University, Kritipur-1, Kathmandu, Nepal. ${ }^{8}$ Institute for Advanced Studies on Asia, The University of Tokyo, 7-3-1 Hongo, Bunkyo-ku, Tokyo 113-0033, Japan. ${ }^{9}$ Center for Vietnamese and Southeast Asian Studies, Vietnam National University of Social Sciences and Humanities, 10-12 Dinh Tien Hoang, Ben Nghe Ward, District 1, Ho Chi 
Minh City, Vietnam. ${ }^{10}$ School of Tropical Medicine and Global Health, Nagasaki University (NCGM Satellite), 1-21-1, Toyama, Shinjuku-ku, Tokyo 162-8655, Japan.

Received: 4 August 2021 Accepted: 29 September 2021 Published online: 08 October 2021

\section{References}

1. Danaei G, Singh GM, Paciorek CJ, Lin JK, Cowan MJ, Finucane MM, et al. The global cardiovascular risk transition: associations of four metabolic risk factors with national income, urbanization, and Western diet in 1980 and 2008. Circulation. 2013;127(14):1493-502 https://www.ahajournals. org/doi/10.1161/CIRCULATIONAHA.113.001470.

2. Hegde SM, Solomon SD. Influence of physical activity on hypertension and cardiac structure and function. Curr Hypertens Rep. 2015;17(10):77 http://link.springer.com/10.1007/s11906-015-0588-3.

3. Hojhabrimanesh A, Akhlaghi M, Rahmani E, Amanat S, Atefi M, Najafi M, et al. A Western dietary pattern is associated with higher blood pressure in Iranian adolescents. Eur J Nutr. 2017;56(1):399-408 http://link.springer. com/10.1007/s00394-015-1090-z.

4. Ibrahim MM, Damasceno A. Hypertension in developing countries. Lancet. 2012;380(9841):611-9 https://linkinghub.elsevier.com/retrieve/ pii/S0140673612608617.

5. World Health Organization. Hypertension [Fact sheet] [Internet]. 2019. https://www.who.int/news-room/fact-sheets/detail/hypertension

6. da Cunha MA, Carneiro MFH, Grotto D, Adeyemi JA, Barbosa F. Arsenic, cadmium, and mercury-induced hypertension: mechanisms and epidemiological findings. J Toxicol Environ Health, Part B. 2018;21(2):61-82 https://www.tandfonline.com/doi/full/10.1080/10937404.2018.1432025.

7. Lin C-Y, Huang P-C, Wu C, Sung F-C, Su T-C. Association between urine lead levels and cardiovascular disease risk factors, carotid intima-media thickness and metabolic syndrome in adolescents and young adults. Int J Hyg Environ Health. 2020;223(1):248-55 https://inkinghub.elsevier.com/ retrieve/pii/S1438463919303943.

8. Eum K-D, Lee M-S, Paek D. Cadmium in blood and hypertension. Sci Total Environ. 2008;407(1):147-53 https://linkinghub.elsevier.com/retrieve/pii/ S0048969708008929.

9. Satarug S, Nishijo M, Lasker JM, Edwards RJ, Moore MR. Kidney dysfunction and hypertension: role for cadmium, P450 and heme oxygenases? Tohoku J Exp Med. 2006;208(3):179-202 https://www.jstage.jst.go.jp/artic le/tjem/208/3/208_3_179/_article.

10. Schiffrin EL, Lipman ML, Mann JFE. Chronic kidney disease. Circulation. 2007;1 16(1):85-97 https://www.ahajournals.org/doi/10.1161/CIRCULATIO NAHA. 106.678342.

11. Vaziri ND. Mechanisms of lead-induced hypertension and cardiovascular disease. Am J Physiol-Heart Circulatory Physiol. 2008;295(2):H454-65 https://www.physiology.org/doi/10.1152/ajpheart.00158.2008.

12. Akther J, Nabi AHMN, Ebihara A. Heavy metals as environmental risk factors for cardiovascular diseases: from the perspective of the renin angiotensin aldosterone system and oxidative stress. Rev Agricull Sci. 2019;7:68-83 https://www.jstage.jst.go.jp/article/ras/7/0/7_68/_article.

13. Kuruppu D, Hendrie HC, Yang L, Gao S. Selenium levels and hypertension: a systematic review of the literature. Public Health Nutr. 2014;17(6):134252 https://www.cambridge.org/core/product/identifier/S136898001 3000992/type/journal_article.

14. Rotruck JT, Pope AL, Ganther HE, Swanson AB, Hafeman DG, Hoekstra WG. Selenium: biochemical role as a component of glutathione peroxidase. Science. 1973;179(4073):588-90 https://www.sciencemag.org/lookup/ doi/10.1126/science.179.4073.588.

15. Yang R, Liu Y, Zhou Z. Selenium and selenoproteins, from structure, function to food resource and nutrition. Food Sci Technol Res. 2017;23(3):36373 https://www.jstage.jst.go.jp/article/fstr/23/3/23_363/_article.

16. Zwolak I, Zaporowska H. Selenium interactions and toxicity: a review. Cell Biol Toxicol. 2012;28(1):31-46 http://link.springer.com/10.1007/ s10565-011-9203-9.

17. Gaschler MM, Stockwell BR. Lipid peroxidation in cell death. Biochem Biophys Res Commun. 2017;482(3):419-25 https://linkinghub.elsevier. com/retrieve/pii/S0006291X16317715.
18. Espinola-Klein C, Rupprecht HJ, Bickel C, Schnabel R, Genth-Zotz S, Torzewski $\mathrm{M}$, et al. Glutathione peroxidase-1 activity, atherosclerotic burden, and cardiovascular prognosis. Am J Cardiol. 2007;99(6):808-12 https:// linkinghub.elsevier.com/retrieve/pii/S0002914906023721.

19. Jin RC, Mahoney CE. (Coleman) Anderson L, Ottaviano F, Croce K, Leopold JA, et al. Glutathione peroxidase-3 deficiency promotes platelet-dependent thrombosis in vivo. Circulation. 2011;123(18):1963-73 https://www. ahajournals.org/doi/10.1161/CIRCULATIONAHA.110.000034.

20. Castiello F, Olmedo P, Gil F, Molina M, Mundo A, Romero RR, et al. Association of urinary metal concentrations with blood pressure and serum hormones in Spanish male adolescents. Environ Res. 2020;182:108958 https://linkinghub.elsevier.com/retrieve/pii/S0013935119307558.

21. Franceschini N, Fry RC, Balakrishnan P, Navas-Acien A, Oliver-Williams C, Howard AG, et al. Cadmium body burden and increased blood pressure in middle-aged American Indians: the Strong Heart Study. J Hum Hypertens. 2017;31(3):225-30 http://www.nature.com/articles/jhh201667.

22. Gambelunghe A, Sallsten G, Borné Y, Forsgard N, Hedblad B, Nilsson P, et al. Low-level exposure to lead, blood pressure, and hypertension in a population-based cohort. Environ Res. 2016;149:157-63 https://linki nghub.elsevier.com/retrieve/pii/S0013935116301876.

23. Satarug S, Nishijo M, Ujjin P, Vanavanitkun Y, Moore MR. Cadmiuminduced nephropathy in the development of high blood pressure. Toxicol Lett. 2005;157(1):57-68 https://linkinghub.elsevier.com/retrieve/pii/S0378 427405000123

24. Whittemore AS, DiCiccio Y, Provenzano G. Urinary cadmium and blood pressure: results from the NHANES II survey. Environ Health Perspect. 1991;91:133-40 https://ehp.niehs.nih.gov/doi/10.1289/ehp.9191133.

25. Skröder H, Hawkesworth S, Kippler M, El Arifeen S, Wagatsuma Y, Moore $\mathrm{SE}$, et al. Kidney function and blood pressure in preschool-aged children exposed to cadmium and arsenic - potential alleviation by selenium. Environ Res. 2015;140:205-13 https://linkinghub.elsevier.com/retrieve/ pii/S0013935115001164.

26. Yao B, Lu X, Xu L, Wang Y, Qu H, Zhou H. Relationship between low-level lead, cadmium and mercury exposures and blood pressure in children and adolescents aged 8-17 years: an exposure-response analysis of NHANES 2007-2016. Sci Total Environ. 2020;726:138446 https://linki nghub.elsevier.com/retrieve/pii/S0048969720319598.

27. Gao Y, Zhu X, Shrubsole MJ, Fan L, Xia Z, Harris RC, et al. The modifying effect of kidney function on the association of cadmium exposure with blood pressure and cardiovascular mortality: NHANES 1999-2010. Toxicol Appl Pharmacol. 2018;353:15-22 https://linkinghub.elsevier.com/retri eve/pii/S0041008X18302448.

28. Ameer SS, Engström K, Harari F, Concha G, Vahter M, Broberg K. The effects of arsenic exposure on blood pressure and early risk markers of cardiovascular disease: evidence for population differences. Environ Res. 2015;140:32-6 https://linkinghub.elsevier.com/retrieve/pii/S001393511500081X.

29. Hossain K, Suzuki T, Hasibuzzaman MM, Islam MS, Rahman A, Paul SK, et al. Chronic exposure to arsenic, LINE-1 hypomethylation, and blood pressure: a cross-sectional study in Bangladesh. Environ Health. 2017;16(1):20 http://ehjournal.biomedcentral.com/articles/10.1186/ s12940-017-0231-7.

30. Islam M, Khan I, Attia J, Hassan S, McEvoy M, D'Este C, et al. Association between hypertension and chronic arsenic exposure in drinking water: a cross-sectional study in Bangladesh. Int J Environ Res Public Health. 2012;9(12):4522-36 http://www.mdpi.com/1660-4601/9/12/4522.

31. Nawrot TS, Staessen JA, Roels HA, Den Hond E, Thijs L, Fagard RH, et al. Blood pressure and blood selenium: a cross-sectional and longitudinal population study. Eur Heart J. 2007;28(5):628-33 https://academic.oup. com/eurheartj/article-lookup/doi/10.1093/eurheartj/eh/479.

32. Li N, Gao Z, Luo D, Tang X, Chen D, Hu Y. Selenium level in the environment and the population of Zhoukoudian area, Beijing, China. Sci Total Environ. 2007;381(1-3):105-11 https://linkinghub.elsevier.com/retrieve/ pii/S0048969707003737.

33. Su L, Jin Y, Unverzagt FW, Liang C, Cheng Y, Hake AM, et al. Longitudinal association between selenium levels and hypertension in a rural elderly Chinese cohort. J Nutr Health Aging. 2016;20(10):983-8 http://link.sprin ger.com/10.1007/s12603-016-0700-7.

34. Vinceti M, Chawla R, Filippini T, Dutt C, Cilloni S, Loomba R, et al. Blood pressure levels and hypertension prevalence in a high selenium environment: results from a cross-sectional study. Nutr Metab Cardiovasc Dis. 
2019;29(4):398-408 https://inkinghub.elsevier.com/retrieve/pii/S0939 475319300213

35. Arnaud J, Akbaraly NT, Hininger I, Roussel A-M, Berr C. Factors associated with longitudinal plasma selenium decline in the elderly: the EVA study. J Nutr Biochem. 2007;18(7):482-7 https://linkinghub.elsevier.com/retrieve/ pii/ $\$ 0955286306002282$.

36. Bulka CM, Persky VW, Daviglus ML, Durazo-Arvizu RA, Argos M. Multiple metal exposures and metabolic syndrome: a cross-sectional analysis of the National Health and Nutrition Examination Survey 2011-2014. Environ Res. 2019;168:397-405 https://linkinghub.elsevier.com/retrieve/ pii/S0013935118305565.

37. Taittonen L, Nuutinen M, Räsänen L, Mussalo-Rauhamaa H, Turtinen J, Uhari M. Lack of association between copper, zinc, selenium and blood pressure among healthy children. J Hum Hypertens. 1997;11(7):429-33 http://www.nature.com/articles/1000466.

38. Borjesson J, Bellander T, Jarup L, Elinder CG, Mattsson S. In vivo analysis of cadmium in battery workers versus measurements of blood, urine, and workplace air. Occup Environ Med. 1997;54(6):424-31 https://oem.bmj. com/lookup/doi/10.1136/oem.54.6.424.

39. Vacchi-Suzzi C, Kruse D, Harrington J, Levine K, Meliker JR. Is urinary cadmium a biomarker of long-term exposure in humans? A review. Curr Environ Health Reports. 2016;3(4):450-8 http://link.springer.com/10.1007/ s40572-016-0107-y.

40. Hughes MF. Biomarkers of exposure: a case study with inorganic arsenic. Environ Health Perspect. 2006;114(11):1790-6 https://ehp.niehs.nih.gov/ doi/10.1289/ehp.9058.

41. Gulson BL, Cameron MA, Smith AJ, Mizon KJ, Korsch MJ, Vimpani G, et al. Blood lead-urine lead relationships in adults and children. Environ Res. 1998;78(2):152-60 https://linkinghub.elsevier.com/retrieve/pii/S0013 93519793810X.

42. Sommar JN, Hedmer M, Lundh T, Nilsson L, Skerfving S, Bergdahl IA Investigation of lead concentrations in whole blood, plasma and urine as biomarkers for biological monitoring of lead exposure. J Expo Sci Environ Epidemiol. 2014;24(1):51-7 http://www.nature.com/articles/jes20134.

43. Alaejos MS, Romero CD. Urinary selenium concentrations. Clin Chem. 1993;39(10):2040-52.

44. Longnecker MP, Stram DO, Taylor PR, Levander OA, Howe M, Veillon C, et al. Use of selenium concentration in whole blood, serum, toenails, or urine as a surrogate measure of selenium intake. Epidemiology. 1996;7(4):384-90 https://journals.lww.com/epidem/Abstract/1996/ 07000/Use_of_Selenium_Concentration_in_Whole_Blood.10.aspx.

45. Wasowicz W, Zachara BA. Selenium concentrations in the blood and urine of a healthy Polish sub-population. Clin Chem Lab Med. 1987;25(7):409-12 https://www.degruyter.com/document/doi/10.1515/ cclm.1987.25.7.409/html.

46. Barr DB, Wilder LC, Caudill SP, Gonzalez AJ, Needham LL, Pirkle JL. Urinary creatinine concentrations in the U.S. population: implications for urinary biologic monitoring measurements. Environ Health Perspect. 2005;113(2):192-200 https://ehp.niehs.nih.gov/doi/10.1289/ehp.7337.

47. Watanabe C, Inaoka T, Kadono T, Nagano M, Nakamura S, Ushijima K, et al. Males in rural Bangladeshi communities are more susceptible to chronic arsenic poisoning than females: analyses based on urinary arsenic. Environ Health Perspect. 2001;109(12):1265-70 https://ehp.niehs.nih.gov/doi/ 10.1289/ehp.011091265.

48. Nordberg GF, Jin T, Hong F, Zhang A, Buchet JP, Bernard A. Biomarkers of cadmium and arsenic interactions. Toxicol Appl Pharmacol. 2005;206(2):191-7 https://linkinghub.elsevier.com/retrieve/pii/S0041 $008 \times 05001018$.

49. Komaromy-Hiller G, Ash KO, Costa R, Howerton K. Comparison of representative ranges based on U.S. patient population and literature reference intervals for urinary trace elements. Clin Chim Acta. 2000;296(12):71-90 https://linkinghub.elsevier.com/retrieve/pii/S00098981000020 59 .

50. Ezaki T, Tsukahara T, Moriguchi J, Furuki K, Fukui Y, Ukai H, et al. No clearcut evidence for cadmium-induced renal tubular dysfunction among over 10,000 women in the Japanese general population: a nationwide large-scale survey. Int Arch Occup Environ Health. 2003;76(3):186-96 http://link.springer.com/10.1007/s00420-002-0389-2.

51. Ikeda M, Zhang Z-W, Shimbo S, Watanabe T, Nakatsuka H, Moon C-S, et al. Exposure of women in general populations to lead via food and air in East and Southeast Asia. Am J Ind Med. 2000;38(3):271-80 https://onlin
elibrary.wiley.com/doi/10.1002/1097-0274(200009)38:3\%3C271::AIDAJIM5\%3E3.0.CO;2-3.

52. Hasunuma R, Tsuda M, Ogawa T, Kawanishi Y. Urinary selenium levels in Japanese males and females. Bull Environ Contam Toxicol. 1990;44(4):501-7 http://link.springer.com/10.1007/BF01700867.

53. Inoue $Y$, Umezaki M, Jiang H, Li D, Du J, Jin Y, et al. Urinary concentrations of toxic and essential trace elements among rural residents in Hainan Island, China. Int J Environ Res Public Health. 2014;1 1(12):13047-64 http://www.mdpi.com/1660-4601/11/12/13047.

54. Shiue I, Hristova K. Higher urinary heavy metal, phthalate and arsenic concentrations accounted for 3-19\% of the population attributable risk for high blood pressure: US NHANES, 2009-2012. Hypertens Res. 2014;37(12):1075-81 http://www.nature.com/articles/hr2014121.

55. Shiue I. Higher urinary heavy metal, arsenic, and phthalate concentrations in people with high blood pressure: US NHANES, 2009-2010. Blood Press. 2014;23(6):363-9 http://www.tandfonline.com/doi/full/10.3109/ 08037051.2014 .925228

56. Shiue I. Higher urinary heavy metal, phthalate, and arsenic but not parabens concentrations in people with high blood pressure, U.S. NHANES, 2011-2012. Int J Environ Res Public Health. 2014;1 1(6):5989-99 http:// www.mdpi.com/1660-4601/11/6/5989.

57. Harari F, Sallsten G, Christensson A, Petkovic M, Hedblad B, Forsgard N, et al. Blood lead levels and decreased kidney function in a populationbased cohort. Am J Kidney Dis. 2018;72(3):381-9 https://linkinghub.elsev ier.com/retrieve/pii/S0272638618305560.

58. Ku E, Lee BJ, Wei J, Weir MR. Hypertension in CKD: Core Curriculum 2019. Am J Kidney Dis. 2019;74(1):120-31 https://linkinghub.elsevier.com/retri eve/pii/S0272638619300940.

59. Nolan CV, Shaikh ZA. Lead nephrotoxicity and associated disorders: biochemical mechanisms. Toxicology. 1992;73(2):127-46 https://linkinghub. elsevier.com/retrieve/pii/0300483X9290097X.

60. Schulz E, Gori T, Münzel T. Oxidative stress and endothelial dysfunction in hypertension. Hypertens Res. 2011;34(6):665-73 http://www.nature.com/ articles/hr201139.

61. Ni Z, Hou S, Barton CH, Vaziri ND. Lead exposure raises superoxide and hydrogen peroxide in human endothelial and vascular smooth muscle cells. Kidney Int. 2004;66(6):2329-36 https://linkinghub.elsevier.com/retri eve/pii/S0085253815503384.

62. Vaziri ND, Ding Y. Effect of lead on nitric oxide synthase expression in coronary endothelial cells. Hypertension. 2001;37(2):223-6 https://www. ahajournals.org/doi/10.1161/01.HYP.37.2.223.

63. Bulka CM, Scannell Bryan M, Persky VW, Daviglus ML, Durazo-Arvizu RA, Parvez $\mathrm{F}$, et al. Changes in blood pressure associated with lead, manganese, and selenium in a Bangladeshi cohort. Environ Pollut. 2019;248:2835 https://linkinghub.elsevier.com/retrieve/pii/S0269749118341812.

64. Jiang J, Liu M, Parvez F, Wang B, Wu F, Eunus M, et al. Association between arsenic exposure from drinking water and longitudinal change in blood pressure among HEALS cohort participants. Environ Health Perspect. 2015;123(8):806-12 https://ehp.niehs.nih.gov/doi/10.1289/ehp.1409004.

65. Li X, Li B, Xi S, Zheng Q, Wang D, Sun G. Association of urinary monomethylated arsenic concentration and risk of hypertension: a crosssectional study from arsenic contaminated areas in northwestern China. Environ Health. 2013;12(1):37 http://ehjournal.biomedcentral.com/artic les/10.1186/1476-069X-12-37.

66. Mendez MA, González-Horta C, Sánchez-Ramírez B, Ballinas-Casarrubias L, Cerón RH, Morales DV, et al. Chronic exposure to arsenic and markers of cardiometabolic risk: a cross-sectional study in Chihuahua, Mexico. Environ Health Perspectives. 2016;124(1):104-11 https://ehp.niehs.nih. gov/doi/10.1289/ehp.1408742.

67. Agusa T, Fujihara J, Takeshita H, Iwata H. Individual variations in inorganic arsenic metabolism associated with AS3MT genetic polymorphisms. Int J Mol Sci. 2011;12(4):2351-82 http://www.mdpi.com/1422-0067/12/4/ 2351

68. Weaver VM, Kim N-S, Jaar BG, Schwartz BS, Parsons PJ, Steuerwald AJ, et al. Associations of low-level urine cadmium with kidney function in lead workers. Occup Environ Med. 2011;68(4):250-6 https://oem.bmj. com/lookup/doi/10.1136/oem.2010.056077.

69. Buser MC, Ingber SZ, Raines N, Fowler DA, Scinicariello F. Urinary and blood cadmium and lead and kidney function: NHANES 2007-2012. Int J Hyg Environ Health. 2016;219(3):261-7 https://linkinghub.elsevier.com/ retrieve/pii/S1438463916000171. 
70. Navas-Acien A, Guallar E, Silbergeld EK, Rothenberg SJ. Lead exposure and cardiovascular disease - a systematic review. Environ Health Perspect. 2007;115(3):472-82 https://ehp.niehs.nih.gov/doi/10.1289/ehp 9785.

71. F. Combs, Jr. G. Biomarkers of selenium status. Nutrients. 2015 31;7(4):2209-36. http://www.mdpi.com/2072-6643/7/4/2209

72. Shimbo S, Zhang ZW, Moon CS, Watanabe T, Nakatsuka H, MatsudaInoguchi N, et al. Correlation between urine and blood concentrations, and dietary intake of cadmium and lead among women in the general population of Japan. Int Arch Occup Environ Health. 2000;73(3):163-70 http://link.springer.com/10.1007/s004200050023.

\section{Publisher's Note}

Springer Nature remains neutral with regard to jurisdictional claims in published maps and institutional affiliations.
Ready to submit your research? Choose BMC and benefit from:

- fast, convenient online submission

- thorough peer review by experienced researchers in your field

- rapid publication on acceptance

- support for research data, including large and complex data types

- gold Open Access which fosters wider collaboration and increased citations

- maximum visibility for your research: over $100 \mathrm{M}$ website views per year

At BMC, research is always in progress.

Learn more biomedcentral.com/submissions 